University of Wollongong

Research Online

Faculty of Engineering and Information

Faculty of Engineering and Information

Sciences - Papers: Part B

Sciences

2019

\title{
Multi-objective optimisation of thermal energy storage using phase change materials for solar air systems
}

Wenye Lin

University of Wollongong, wenye@uow.edu.au

Zhenjun $\mathrm{Ma}$

University of Wollongong, zhenjun@uow.edu.au

Haoshan Ren

University of Wollongong, hr681@uowmail.edu.au

Stefan Gschwander

Fraunhofer Institute for Solar Energy Systems ISE

Shugang Wang

Dalian University of Technology, shugang@uow.edu.au

Follow this and additional works at: https://ro.uow.edu.au/eispapers1

Part of the Engineering Commons, and the Science and Technology Studies Commons

Research Online is the open access institutional repository for the University of Wollongong. For further information contact the UOW Library: research-pubs@uow.edu.au 


\title{
Multi-objective optimisation of thermal energy storage using phase change materials for solar air systems
}

\author{
Abstract \\ Thermal energy storage (TES) using phase change materials (PCMs) is being widely considered as one of \\ the alternative solutions for effective use of solar energy. This paper presents a multi-objective \\ optimisation strategy for TES systems using PCMs for solar air systems, in which two performance \\ indicators of average heat transfer effectiveness and effective PCM charging time were used as the \\ conflicting objectives. The influence of the key design variables on the performance of an air-based PCM \\ TES system was first experimentally investigated using Taguchi method, and the results were used to \\ develop two performance models for optimisation. A genetic algorithm was used to search for an optimal \\ Pareto front and a multi-criteria decision-making process was employed to determine the compromise \\ optimal solutions. The results showed that the average heat transfer effectiveness of the PCM TES \\ system can be improved from 44.25 to $59.29 \%$ while the effective PCM charging time increased from 4.53 \\ to $6.11 \mathrm{~h}$ when using the solutions identified by the proposed strategy with the weighting factors of $0.5 /$ \\ 0.5 for both objectives, in comparison to a baseline case. A further comparison showed that the optimal \\ design identified by the proposed strategy outperformed the two designs identified using Taguchi \\ method. \\ Disciplines \\ Engineering | Science and Technology Studies

\section{Publication Details} \\ Lin, W., Ma, Z., Ren, H., Gschwander, S. \& Wang, S. (2019). Multi-objective optimisation of thermal energy \\ storage using phase change materials for solar air systems. Renewable Energy, 130 1116-1129.
}

This journal article is available at Research Online: https://ro.uow.edu.au/eispapers1/1785 


\title{
Multi-objective optimisation of thermal energy storage using
}

\section{phase change materials for solar air systems}

\author{
Wenye Lin ${ }^{1}$, Zhenjun Ma ${ }^{*}, 1$, Haoshan Ren ${ }^{1}$, Stefan Gschwander ${ }^{2}$, Shugang Wang ${ }^{3}$ \\ ${ }^{1}$ Sustainable Buildings Research Centre (SBRC), University of Wollongong, 2522, Australia \\ ${ }^{2}$ Fraunhofer Institute for Solar Energy Systems (ISE), Freiburg, 79110, Germany \\ ${ }^{3}$ Faculty of Infrastructure Engineering, Dalian University of Technology, 116024, China \\ *Email: zhenjun@uow.edu.au
}

Abstract: Thermal energy storage (TES) using phase change materials (PCMs) is being widely considered as one of the alternative solutions for effective use of solar energy. This paper presents a multi-objective optimisation strategy for TES systems using PCMs for solar air systems, in which two performance indicators of average heat transfer effectiveness and effective PCM charging time were used as the conflicting objectives. The influence of the key design variables on the performance of an air-based PCM TES system was first experimentally investigated using Taguchi method, and the results were used to develop two performance models for optimisation. A genetic algorithm was used to search for an optimal Pareto front and a multi-criteria decision-making process was employed to determine the compromise optimal solutions. The results showed that the average heat transfer effectiveness of the PCM TES system can be improved from 44.25 to $59.29 \%$ while the effective PCM charging time increased from 4.53 to 6.11 hours when using the solutions identified by the proposed strategy with the weighting factors of $0.5 / 0.5$ for both objectives, in comparison to a baseline case. A further comparison showed that the optimal design identified by the proposed strategy outperformed the two designs identified using Taguchi method.

Keywords: Phase change materials; Thermal energy storage; Experimental investigation; Multi-objective optimisation; Decision-making 


\section{Nomenclature}

$27 A$ heat transfer area $\left(\mathrm{m}^{2}\right)$

$28 A_{p} \quad$ cross-section area of the air channels $\left(\mathrm{m}^{2}\right)$

$29 \quad a_{0-3} \quad$ coefficients

$30 \quad b_{0-3} \quad$ coefficients

$31 \quad c_{p} \quad$ specific heat capacity $(\mathrm{J} /(\mathrm{kg} \cdot \mathrm{K}))$

$32 \quad d_{h} \quad$ hydraulic diameter $(\mathrm{m})$

$33 f_{t j} \quad$ the $i^{\text {th }}$ criterion for the $j^{\text {th }}$ alternative design

$34 f_{t}^{*} \quad$ the best value of the $i^{\text {th }}$ criterion

$35 f_{i}^{-} \quad$ the worst value of the $i^{\text {th }}$ criterion

$36 H$ height of the air channels (m)

$37 h_{\text {conv }} \quad$ convective heat transfer coefficient $\left(\mathrm{W} /\left(\mathrm{m}^{2} \cdot \mathrm{K}\right)\right)$

$38 k$ thermal conductivity $(\mathrm{W} /(\mathrm{m} \cdot \mathrm{K}))$

$39 \quad L_{P C M} \quad$ length of the PCM brick (m)

$40 M \quad$ number of the PCM bricks in the direction of air flow

$41 m \quad$ number of criterion

$42 \quad m_{P C M} \quad$ mass of each PCM brick $(\mathrm{kg})$

$43 \quad$ number of the air channels

$44 \quad \mathrm{Nu} \quad$ Nusselt number

$45 n \quad$ number of the observations

$46 \quad n_{t} \quad$ total sampling number

$47 \quad P \quad$ wetted perimeter of the air channels (m)

$48 \quad \operatorname{Pr} \quad$ Prandtl number

$49 \quad$ heat transfer (J) 


\begin{tabular}{|c|c|c|}
\hline 50 & $Q$ & heat transfer rate $(\mathrm{J} / \mathrm{h})$ \\
\hline 51 & $Q_{v}$ & volume air flow rate $(1 / s)$ \\
\hline 52 & $Q_{j}$ & scale quantity $L_{c o m}-m e t r i c$ \\
\hline 53 & $R_{j}$ & scale quantity $L_{\infty}$-metric \\
\hline 54 & $R^{*}$ & minimal value of $R_{j}$ \\
\hline 55 & $R^{-}$ & maximal value of $R_{j}$ \\
\hline 56 & $R e$ & Reynolds number \\
\hline 57 & $S_{j}$ & scale quantity $L_{1}$-metric \\
\hline 58 & $S^{*}$ & minimal value of $S_{j}$ \\
\hline 59 & $S^{-}$ & maximal value of $S_{j}$ \\
\hline 60 & $T$ & temperature $\left({ }^{\circ} \mathrm{C}\right)$ \\
\hline 61 & $T_{m}$ & nominal phase change temperature $\left({ }^{\circ} \mathrm{C}\right)$ \\
\hline 62 & $\Delta t_{c h}$ & effective PCM charging time $(\mathrm{h})$ \\
\hline 63 & $t$ & time $(\mathrm{h})$ \\
\hline 64 & $v$ & weight for the strategy of "the majority of criteria" \\
\hline 65 & $U$ & overall heat transfer coefficient $\left(\mathrm{W} /\left(\mathrm{m}^{2} \cdot \mathrm{K}\right)\right)$ \\
\hline 66 & $W$ & width of the TES unit (m) \\
\hline 67 & $W_{P C M}$ & width of the PCM brick (m) \\
\hline 68 & $w_{i}$ & weight of the $i^{\text {th }}$ criterion \\
\hline 69 & $y_{T, z}$ & the $z^{\text {th }}$ observed objective response \\
\hline 70 & \multicolumn{2}{|c|}{ Greek letters } \\
\hline 71 & $\gamma$ & specific heat of fusion $(\mathrm{J} / \mathrm{kg})$ \\
\hline 72 & $\varepsilon_{c h}$ & heat transfer effectiveness \\
\hline 73 & $\bar{\varepsilon}_{c h}$ & average heat transfer effectiveness \\
\hline 74 & $\rho$ & density $\left(\mathrm{kg} / \mathrm{m}^{3}\right)$ \\
\hline
\end{tabular}




\section{Subscripts}

in inlet

lat latent

out outlet

sen sensible

tot total

\section{Introduction}

The increasing greenhouse gas emissions, aggravating primary energy shortage and continuously growing energy demand are among the major public concerns over the last decade [1]. Buildings are one of the major energy consumers and account for as much as $45 \%$ of the global energy usage with a similar share of the greenhouse gas emissions [2]. A significant proportion of energy used in buildings is for heating, ventilation and air conditioning (HVAC) [3]. The development and deployment of advanced energy technologies and the improvement in energy efficiency of HVAC systems have been recognised as feasible approaches to significantly reducing building energy consumption and achieving sustainability of the built environment [4-7].

Solar air systems have been considered as an alternative energy system for space heating. As solar energy is intermittent, the integration of solar air systems with thermal energy storage (TES) systems is therefore essential to rationalising the energy management [8]. Over the last two decades, TES systems using phase change materials (PCMs) have been receiving increasing attention. PCMs with high energy storage densities can store a large amount of thermal energy and release it for later use at a relatively constant temperature. Extensive research has been performed on integrating PCM TES units with solar air systems for building applications [9-12]. For instance, a vertical PCM TES system was designed by Chen 
et al. [9] and employed as part of a solar-PCM fresh air heating system for office buildings.

The experimental results showed that $93 \%$ of the thermal energy stored in the PCM TES unit can be extracted during the thermal discharge process and used for fresh air heating. A ceiling ventilation system integrated with solar photovoltaic thermal (PVT) collectors and PCMs was studied by Lin et al. [10], in which the PCM was embedded into the building ceiling as part of the ceiling insulation and, at the same time, as a centralised TES system. It was found that the indoor thermal performance of a house using the PVT-PCM ceiling ventilation system was better than that of the original house without using PVT and PCMs for space heating. Fiorentini et al. [11] developed an HVAC system with integrated PVT collectors and a PCM TES system for a net-zero energy retrofitted house. The performance of the HVAC system was improved with the assistance of the PVT collectors and the PCM TES unit. Stritih et al. [12] carried out experimental and numerical investigations of a PCM TES system heated by a building-integrated solar air collector for indoor space heating. The result showed that a maximal energy saving of $92 \%$ can be reached by reducing the ventilation heat loss through using this proposed system. The results from the above studies showed that integration of PCM TES units with solar air systems can overcome the intermittency of solar energy, and can therefore improve overall system performance and provide better indoor thermal comfort due to the effective thermal energy regulation of the PCM TES unit.

Since the effectiveness and good performance of a PCM TES system cannot be achieved without appropriate design, the effects of key parameters on the performance of the PCM TES systems and optimal design of such systems have been extensively studied. Dolado et al. [13] carried out a systematic performance characterisation of a PCM TES unit with a matrix of PCM slabs. It was highlighted that the desired heat transfer of the PCM TES unit can be achieved by optimising the air flow rate, the rugosity of the slab surface, the PCM slab thickness, the length of the PCM unit or the air gap between the PCM slabs. A parametric 
study of a PCM-based solar air system for residential space heating was carried out by Waqas and Kumer [14]. It was found that the most sensitive parameters affecting the performance of the TES unit were the melting point of the storage material, mass of the PCM, and air flow rate. Diarce et al. [15] developed a correlation relating the discharging time of a plate-based PCM TES system with the PCM slab thickness based on a series of CFD simulations. This correlation can allow the direct determination of the suitable PCM plate thickness. Ren et al. [16] evaluated the thermal performance of an air-based PCM TES unit coupled with PVT collectors. It was found that the PCM type and the PCM charging air flow rate were the most important factors influencing the useful energy stored in the TES system. Amin et al. [17] optimised the design of an air-based PCM TES system through a parametric study. In this study, a performance indicator combining the heat transfer effectiveness and the energy storage density was proposed and used as the optimisation objective to maximise the utilisation of thermal storage media. A roof solar heating system with an integrated PCM TES unit was studied by Saman et al. [18]. It was concluded that the inlet air temperature and air flow rate were the two key factors influencing the heat transfer rate and melting time of the PCM TES system. The performance of a PCM-based TES unit for solar air systems was experimentally and numerically investigated by Charvat et al. [19]. It was found that both the heat storage rate and the charging time of the TES unit increased with the increase of the number of the air channels. It is therefore important to select more than one optimisation objective in the development of the optimisation problems for PCM TES units. It can be seen from the aforementioned studies that when integrating PCM TES units with solar systems, a fast charging process together with a good heat transfer performance of the PCM TES unit becomes essential in order to rationalise the utilisation of solar energy. It can also be concluded that PCM properties, operation parameters (e.g. inlet air temperature and the air flow rate), geometric parameters of the PCM TES system (e.g. number and size of air 
channels, thickness of PCM slabs and length of the PCM TES) are among the most significant

151

152

153

154

155

156

157

158

159

160

161

162

163

164

165

166

167

168 parameters influencing the performance of PCM TES systems.

Optimisation algorithms coupled with performance prediction is a process-oriented tool to identify the optimal values of the design variables of a system of concern [20]. Multiobjective optimisation has been considered as an effective approach for optimal design of buildings and building services systems [21, 22]. For instance, the elitist non-dominated sorting genetic algorithm (NSGA-II) was used by Padovan and Manzan [21] to optimise a PCM-enhanced water storage tank for solar domestic hot water systems. Compared to a single-objective optimisation which only resulted in a slightly lower primary consumption of domestic hot water, both the primary consumption and gross volume of the TES tank can be reduced by using a multi-objective optimal design. A multi-objective design optimisation strategy using a genetic algorithm for vertical U-tube ground heat exchangers was proposed and used by Huang et al. [22] to minimise the upfront cost and entropy generation number (EGN) of a ground source heat pump system. It was found that the upfront cost can be reduced by $9.5 \%$ even with a slightly higher EGN when the multi-objective design optimisation strategy was implemented, as compared with using EGN as the single objective. A hybrid Hooke-Jeeves and Particle Swarm Optimisation algorithm was used by Futrell et al. [24] for bi-objective optimisation of building thermal performance and lighting performance. This bi-objective optimisation resulted in a Pareto front on which neither objective can be improved without worsening the other, allowing decision makers to evaluate the trade-offs between the daylighting performance and thermal performance. A NSGA-II with two novel termination criteria was employed by Wong et al. [25] to optimally design a shell-and-tube heat exchanger. The trade-off between the capital cost and operating cost was considered in the bi-objective optimisation, and the multi-objective optimal design outperformed a singleobjective optimal design [26]. A multi-objective optimisation of a forced draft cooling tower 
using NSGA-II was performed by Singh and Das [27] to optimise the performance parameters including the temperature range of cooling water, the tower characteristic ratio, the

effectiveness and the water evaporation rate simultaneously. An optimal Pareto front was achieved through the multi-objective optimisation, based on which a decision-making procedure was further implemented to identify a unique optimal design according to the priorities assigned to different performance parameters. The above results showed that multiobjective optimisation taking into account more than one objective in the optimisation problem can result in a more reasonable solution by considering the trade-off between the conflicting objectives. However, only a very limited number of existing studies used multiobjective optimisation to optimise the PCM TES units, and in particular there is a lack of using an experimental approach to facilitating the multi-objective optimal design of air-based PCM TES units.

This paper presents a multi-objective design optimization strategy for PCM TES units used in solar air systems. Different from most existing studies, the optimisation strategy was developed based on the experimental characterisation and parameter regression. A range of experiments was first designed using Taguchi method and carried out based on a lab-scale test rig to evaluate the system performance and facilitate the formulation of the multi-objective optimisation problem. A multi-objective optimisation and a multi-criteria decision-making process were then used to determine the optimal solution of the optimisation problem. The proposed multi-objective optimisation strategy can provide an experimental oriented procedure to facilitate the optimal design of air-based PCM TES units for solar air systems with conflicting optimisation objectives.

\section{Description of the experimental system}

\subsection{Experimental setup}


To understand the charging performance of the PCM TES unit, a range of experiments were first carried out based on a lab-scale test rig, as shown in Fig. 1. This test rig consisted of a chiller, a PVT emulator, a PCM TES unit, a PCM fan, a heat exchanger, and several dampers. The PVT emulator utilizes an electric heater and a variable speed fan (named as PVT fan) to mimic a PVT system and the outlet air from the PVT emulator was used to charge the PCM TES unit. The air flow rate through the PVT emulator was controlled by varying the PVT fan speed while the temperature of the outlet air from the PVT emulator was controlled by regulating the heat output of the electric heater through a Proportional-Integral (PI) controller. The rated air flow of the PVT fan was $300 \mathrm{l} / \mathrm{s}$. The heat exchanger, chiller and PCM fan were used to discharge the heat from the PCM TES unit. The PCM fan used was the same as the PVT fan. Several dampers were used to switch the system between the charging mode and discharging mode (Fig. 1b).

The PCM TES unit tested was a rectangular duct made of wood, which was thermally insulated with polyolefin materials. The internal dimensions of the PCM TES duct were approximately $2500 \mathrm{~mm}$ (length), $215 \mathrm{~mm}$ (width) and $250 \mathrm{~mm}$ (height), respectively. The PCM bricks can be placed inside this PCM TES unit in arrays to create different numbers of air channels, as shown in Fig. 2a). The PCM tested was a commercial salt hydrate of S21 supplied from PlusICE [28], which was encapsulated in the plastic containers as the PCM bricks (Fig. 2 b)). The PCM S21 was used in this study as its phase change temperature is close to the indoor thermal comfort temperature so that the thermal energy stored in the PCM can be directly usedfor indoor space heating. The thermophysical properties of this PCM S21 are summarised in Table 1. The PCM brick was $500 \mathrm{~mm}$ long by $32 \mathrm{~mm}$ wide by $250 \mathrm{~mm}$ high. The rectangular TES duct used can allow a maximum of five PCM bricks to be placed in the direction of the air flow. The number of PCM bricks across the direction of the air flow depends on the size of the air channels selected. 
In this test rig, the heated air from the PVT emulator can be directed into the PCM TES unit for heat charging and then discharged to ambient by opening the dampers V2 and V3 (Fig. $1 \mathrm{~b})$ ). In the discharging mode, the system can operate either under Option $A$ using the circulation air by opening the dampers V4, V5 and V6 or under Option B using ambient air by opening the dampers $\mathrm{V} 7, \mathrm{~V} 5, \mathrm{~V} 4, \mathrm{~V} 2$ and $\mathrm{V} 1$, dependent on the temperature of ambient air (Fig. $1 \mathrm{~b})$ ). It is worthwhile to mention that, during the experiments, the air flow directions in the charging mode and discharging mode were opposite, so that a desired heat transfer performance during the discharge of the PCM TES unit could be achieved. In this study, the Option A was used during the test in order to minimise the influence of ambient conditions.

\subsection{Measurement instruments}

Five temperature sensors were used to measure the temperature of the outlet air from the PVT emulator (i.e. temperature sensor \#1 in Fig. 1 b)), and the air temperatures at both ends of the PCM TES unit (i.e. temperature sensors \#2 and \#5), as well as the PCM temperatures of the two PCM bricks at each end of the PCM TES unit (see Fig. 1 b)). A stainless steel tube bracketed on the outside of the PCM brick was inserted into the PCM brick to prevent the tube from moving inside the brick and the temperature sensor from being corroded by the PCM (Fig. 3). The steel tube was partially filled with thermal paste prior to the insertion of the temperature sensor. A differential pressure transmitter was used to measure the pressure loss along the PCM TES unit. An air velocity sensor was used to measure the air velocity inside the air duct.

A CLIPSAL C-Bus residential controller was used to control the fan speed and the heating power of the electrical heater, and record the measured data based on PICED software and CLIPSAL [29]. The sampling rate used in the experimental tests was 30 seconds. The key measurement instruments used and their corresponding uncertainties are summarised in Table 2. 


\section{Methodology}

\subsection{Outline of the methodology}

The research methodology used in this study is outlined in Fig. 4. It consisted of two major steps. The first step was the experimental investigation of charging and discharging characteristics of the PCM TES unit with a primary focus on the PCM charging performance because the temperature and air flow rate of the heated air from the PVT emulator can be well controlled within a relatively wide range. A matrix of experiments was first designed using Taguchi method and then carried out based on the lab-scale test rig introduced in Section 2. Signal-to-noise $(S / N)$ ratio was used to analyse the performance of the PCM TES unit based on the two key performance indicators (KPIs) of the average heat transfer effectiveness and the effective charging time of the PCM TES unit, which will be introduced in Section 3.2.1. Based on the experimental results, the charging characteristics of the PCM TES unit and the optimal combination of the factor levels corresponding to each KPI can be identified and the significance of the control factors to each KPI can also be ranked. Two performance models relating each KPI to the key variables were established based on some assumptions, which will be presented in Section 3.2.2. The experimental data were then used to regress the coefficients in the two performance models through the stepwise regression.

The second step was the optimisation of the PCM TES unit. Since the discrete factor levels were used in the Taguchi experimental plan and the optimal factor levels identified through $S / N$ ratio analysis were only near-optimal for each individual KPI, a multi-objective optimisation was therefore used to further identify the compromise optimal values of the key variables of the PCM TES unit by considering the trade-off between the two KPIs. The two performance models developed were then used to formulate the multi-objective optimisation problem. A controlled elitist genetic algorithm was used as the optimisation technique to identify an optimal Pareto front based on the constraints defined. In the Pareto front, each 
combination of the optimisation objectives could be considered as optimal and a multi-criteria decision-making process was therefore used to determine the compromise optimal solution of the optimisation problem, which is introduced in Section 3.4.

\subsection{Experimental design, key performance indicators and data analysis method}

\subsubsection{Experimental design using Taguchi method}

Taguchi method [30] is an experimental design technique which uses an orthogonal array to form a matrix of experiments, and has been widely used for experimental design, analysis of experiments, sensitivity study and system design optimisation. In Taguchi method, multiple control factors and certain levels of the control factors are arranged orthogonally so that only a minimal fraction of the full-factorial trial tests need to be conducted.

In this study, the following four key variables were considered to be the control factors: the inlet air temperature of the PCM TES unit, the air flow rate, the number of PCM bricks in the direction of air flow and the number of air channels of the PCM TES unit. The number of PCM bricks in the direction of air flow was used to represent the length of the PCM TES unit, which was considered as a discrete variable in this study.

Three levels were considered for each factor. The three levels of the inlet air temperature of the PCM TES unit used in the charging mode were $42^{\circ} \mathrm{C}, 37^{\circ} \mathrm{C}$ and $32^{\circ} \mathrm{C}$, which were determined based on the 20,15 and $10^{\circ} \mathrm{C}$ difference in the temperature between the inlet air of the TES unit and the nominal PCM phase change temperature (i.e. $22^{\circ} \mathrm{C}$ ), respectively. The three levels of the air flow rate used during the charging mode were 150, 100 and $50 \mathrm{l} / \mathrm{s}$, respectively. The levels of the number of PCM bricks in the direction of air flow considered were 3, 4 and 5, while that of the number of the air channels considered were 3,4 and 5, respectively. The air flow rate, the number of PCM bricks in the direction of air flow and the number of air channels were determined based on the capacity of the PVT fan, the size of the PCM duct and the dimension of the PCM brick tested. The $L_{9}\left(3^{4}\right)$ orthogonal array was used 
to form a matrix of the trial tests and the resulting experimental design is presented in Table 3 .

As mentioned before, the primary focus of this study was on the PCM charging performance.

During the discharging mode, the maximum airflow rate that the PCM fan can deliver was used and the air used to discharge the PCM was generally cooled below $14^{\circ} \mathrm{C}$ using the heat exchanger and the chiller in order to reduce the discharging time.

\subsubsection{Key performance indicators}

In this study, two key performance indicators, namely the average heat transfer effectiveness and the effective PCM charging time, were defined and used as the objective responses to evaluate the charging performance of the PCM TES unit.

\section{Average heat transfer effectiveness}

Heat transfer effectiveness has been used in several studies to examine the performance of TES systems [31-33]. In this study, the average heat transfer effectiveness of the PCM TES over the PCM charging period was used as a KPI, which was the average ratio of the actual heat transfer rate into the TES system to the theoretical maximum heat transfer rate during the phase change process and was determined by Eq. (1).

$$
\bar{\varepsilon}_{c h}=\frac{1}{\Delta t_{c h}} \int_{t_{\text {satur }}}^{t_{\text {end }}} \varepsilon_{c h} d t=\frac{1}{\Delta t_{c h}} \int_{t_{\text {start }}}^{t_{\text {end }}} \frac{T_{\text {air }, \text { in }}-T_{\text {air }, \text { out }}}{T_{\text {air }, \text { in }}-T_{m}} d t \approx \frac{1}{n_{t}} \sum_{i=1}^{n_{t}} \frac{\left(T_{\text {air }, \text { in }, i}-T_{\text {air }, \text { out }, i}\right)}{\left(T_{\text {air }, \text { in }, i}-T_{m}\right)}
$$

where $\varepsilon_{c h}$ is the heat transfer effectiveness, $T$ is the temperature, $T_{m}$ is the PCM nominal melting temperature, $n_{t}$ is the total sampling number during the charging period, $t_{\text {start }}$ and $t_{\text {end }}$ represent the start time and completion time defined for the effective PCM charging period $\left(\Delta t_{c h}\right)$, and the subscripts in and out indicate inlet and outlet, respectively.

\section{Effective PCM charging time}

As many conventional PCMs, especially organic PCMs, have a significant disadvantage of low thermal conductivity, which makes them difficult to address the rapid load changes during the thermal charging and discharging processes [34], the effective PCM charging time was therefore developed and used as another KPI to evaluate the charging performance of the 
PCM TES unit. In this study, the effective PCM charging time was the difference in time when the temperature gradient of the first PCM brick close to the inlet of the TES unit suddenly decreases (after which the first PCM brick experiences a relatively small change in temperature gradient for certain period during the charging process), and when the temperature gradient of the last PCM brick close to the outlet of the TES unit suddenly increases (before which the last PCM brick experiences a relatively small change in temperature gradient for certain period during the charging process).

Both of the KPIs used may not be perfect but they could provide an indication of the performance of the PCM TES unit under different working conditions. The average heat transfer effectiveness was expected to be the-higher-the-better, while the effective PCM charging time was expected to be the-lower-the better in this study.

It is worthwhile to mention that although the PCM TES unit was well insulated, the heat loss through the PCM TES unit still existed, and since the amount was difficult to quantify, the heat loss was omitted. Moreover, to ensure the two KPIs developed were valid, the initial PCM temperature in each experiment was held well below the low limit of the PCM phase change temperature range, while the inlet air temperature used to charge the PCMs was much higher than the upper limit of the PCM phase change temperature range.

\subsubsection{Data analysis method}

$S / N$ ratio analysis in Taguchi method was used to identify the importance of the factors considered, which was ranked according to the maximal $S / N$ ratio difference between the different levels of each factor. $S / N$ ratios of the average heat transfer effectiveness and the effective PCM charging time, which were expected to be the-higher-the-better and the-lowerthe-better, are calculated using Eqs. (2) and (3), respectively [30]. $S / N$ ratio was also used to identify the best combination of the levels of each individual factor, which can be considered 
as an optimisation process. However, since the $S / N$ ratio analysis can only handle singleobjective optimisation, the optimisation for each KPI needs to be carried out individually.

$$
\begin{aligned}
& S / N=-10 \log \left(\frac{1}{n} \sum_{z=1}^{n} \frac{1}{y_{T, z}^{2}}\right) \\
& S / N=-10 \log \left(\frac{1}{n} \sum_{z=1}^{n} y_{T, z}^{2}\right)
\end{aligned}
$$

where $y_{T, z}$ is the $z^{\text {th }}$ observed objective response from the Taguchi trial tests, and $n$ is the number of the observations in a trial test.

\subsection{Formulation of the multi-objective optimisation problem}

\subsubsection{Optimisation objectives, and optimisation variables and constraints}

In the multi-objective optimisation, the average heat transfer effectiveness and the effective PCM charging time were used as the two optimisation objectives. The four factors used in the Taguchi experimental design were considered as the optimisation variables. The constraints of the optimisation variables are defined below, which were determined based on the factor levels considered in the Taguchi experimental design.

$$
\left\{\begin{array}{l}
T_{\text {air }, i n} \in[32.0,42.0]^{\circ} \mathrm{C} \\
\dot{Q}_{v} \in[50.0,150.0] 1 / \mathrm{s} \\
M \in\{3,4,5\} \\
N \in\{3,4,5\}
\end{array}\right.
$$

where $M$ is the number of PCM bricks in the direction of air flow and $N$ is the number of air channels.

\subsubsection{Development of the performance models}

Two performance models which related the optimisation objectives to the optimisation variables were developed and used to estimate how the system would respond under different trail settings. 
The performance model of the average heat transfer effectiveness was established based on the PCM nominal melting temperature during the thermal charging process. The average heat transfer effectiveness $\left(\bar{\varepsilon}_{c h}\right)$ between the PCM bricks and the air flowing through the PCM TES unit was determined by Eq. (4), in which overall heat transfer coefficient $(U)$ was assumed to follow a third-order polynomial of the convective heat transfer coefficient $\left(h_{\text {conv }}\right)$, and is described in Eq. (5). The convective heat transfer coefficient was determined using Eq. (6), in which Nusselt number $\left(N_{u}\right)$ was calculated using Eq. (7), and the hydraulic diameter $\left(d_{h}\right)$ was given by Eq.(8). The heat transfer area is determined using Eq. (9).

$$
\begin{aligned}
& \bar{\varepsilon}_{c h}=1-e^{-N T U}=1-e^{-\frac{1000 \cdot A U}{\rho_{\text {air }} C_{p, a i r} \dot{Q}_{v}}} \\
& U=a_{3} h_{\text {conv }}^{3}+a_{2} h_{\text {conv }}^{2}+a_{1} h_{c o n v}+a_{0} \\
& h_{\text {conv }}=\frac{N u \cdot k_{\text {air }}}{d_{h}} \\
& N u=0.023 \operatorname{Re}^{0.8} \operatorname{Pr}^{0.3} \\
& d_{h}=\frac{4 A_{p}}{P}=\frac{4 H \cdot\left[W-(N-1) \cdot W_{P C M}\right]}{2\left\{\left[W-(N-1) \cdot W_{P C M}\right]+N \cdot H\right\}} \\
& A=2(N-1) \cdot M \cdot H \cdot L_{P C M}
\end{aligned}
$$

where $c_{p, \text { air }}$ is the air specific heat, $\rho_{\text {air }}$ is the air density, $Q_{v}$ is the air volume flow rate, $A$ is the heat transfer area, $k_{\text {air }}$ is the air thermal conductivity, $A_{p}$ is the cross-sectional area of the air channels, $P$ is the wetted perimeter of the air channels, $R e$ is Reynolds number, $P r$ is Prandtl number, $H$ is the height of the air channel which is equal to the height of the PCM brick in this study, $W$ is the width of the TES unit, $W_{P C M}$ and $L_{P C M}$ are the width and length of the PCM bricks, respectively, and $a_{0^{-}} a_{3}$ are the coefficients which were regressed based on the results of the Taguchi experiments using the stepwise regression.

The effective PCM charging time was determined based on the total thermal energy $\left(Q_{t o t}\right)$ stored in the PCM TES unit and the average heat transfer rate, and is defined in Eq. (10). The 
average heat transfer rate $(Q)$ and the latent heat $\left(Q_{\text {lat }}\right)$ stored in the PCM TES unit were

392

393 determined using Eqs. (11) and (12), respectively. The ratio of the sensible heat $\left(Q_{s e n}\right)$ to the average heat transfer rate was calculated using Eq. (13), which was determined through the stepwise regression.

$$
\Delta t_{c h}=\frac{Q_{t o t}}{\dot{Q}}=\frac{Q_{l a t}}{\dot{Q}}+\frac{Q_{s e n}}{\dot{Q}}
$$

$$
\dot{Q}=3.6 \times \rho_{\text {air }} c_{p, \text { air }} \dot{Q}_{v}\left(T_{\text {air }, \text { in }}-T_{\text {air }, \text { out }}\right)=3.6 \times \rho_{\text {air }} c_{p, \text { air }} \dot{Q}_{v} \bar{\varepsilon}_{c h}\left(T_{\text {air }, \text { in }}-T_{m}\right)
$$

$$
Q_{\text {lat }}=m_{P C M} M(N-1) \gamma
$$

where $\bar{\varepsilon}_{c h}$ is the average heat transfer effectiveness calculated by Eq. (4), $\gamma$ is the PCM latent heat of fusion, $m_{P C M}$ is the mass of each PCM brick, $b_{0}-b_{3}$ are the coefficients regressed based on the results of the Taguchi experiments using the stepwise regression, and the subscripts tot, lat and sen represent total, latent and sensible, respectively.

\subsubsection{Multi-objective genetic algorithm optimisation technique}

The elitist non-dominated Sorting Genetic Algorithm (NSGA-II) as an optimisation technique has been used in several studies to solve multi-objective optimisation problems [25, 26, 35]. In this study, a variant of elitist NSGA-II implemented in Matlab (i.e. function 'gamultiobj'), was used as the optimisation technique to solve the multi-objective optimisation problem. The 'gamultiobj' function employs two options, the 'ParetoFraction' and the 'DistanceFcn', to maintain diversity by controlling the number of individuals on the Pareto front and by favouring individuals that are some distance away on the front, respectively [36].

\subsection{Multi-criteria decision-making using the compromise ranking method}

The compromise ranking method, VIKOR, introduced by Opricovic [37], was used for decision-making to determine the compromise optimal solution(s) on the Pareto front 
identified. This method identifies the compromise design(s) among a set of alternatives in the presence of the conflicting criteria by ranking them based on their distance from the ideal solution [38]. This distance is measured by three scalar quantities (i.e. $S_{j}, R_{j}$ and $Q_{j}$, known as $L_{1}$-metric, $L_{\infty}$-metric and $L_{c o m}$-metric, respectively) and calculated using Eqs. (14)-(16) for each alternative [39].

$$
\begin{aligned}
& S_{j}=\sum_{i=1}^{m} w_{i}\left(f_{i}^{*}-f_{i j}\right) /\left(f_{i}^{*}-f_{i}^{-}\right) \\
& R_{j}=\max _{i}\left[w_{i}\left(f_{i}^{*}-f_{i j}\right) /\left(f_{i}^{*}-f_{i}^{-}\right)\right] \\
& Q_{j}=v\left(S_{j}-S^{*}\right) /\left(S^{-}-S^{*}\right)+(1-v)\left(R_{j}-R^{*}\right) /\left(R^{-}-R^{*}\right)
\end{aligned}
$$

where $f_{t f}$ is the $i^{\text {th }}$ criterion for the $j^{\text {th }}$ alternative, $m$ is the number of criterion, $w_{i}$ is the weight of the $i^{t h}$ individual criterion, $v$ is the weight of the strategy of "the majority of criteria" ranging from 0 to $1, f_{t}^{*}$ and $f_{i}^{-}$are the best and worst values of all criterion functions, and $S^{*}$, $S^{-}, R^{*}$ and $R^{-}$are the minimal and maximal values of $S_{j}$ and $R_{j}$, respectively.

Based on the three scalar quantities, three ranking lists can be generated in a decreasing order and the compromise designs can be identified based on the ranking lists. The details of this method can be found in Opricovic and Tzeng [38].

\section{Experimental results and discussions}

\subsection{Differential Scanning Calorimetry (DSC) test}

A DSC test was carried out to determine the phase change melting range and the enthalpytemperature (h-T) relationship of the PCM S21. Fig. 5 a) illustrates the DSC test results under a scanning rate of $0.05 \mathrm{~K} / \mathrm{min}$. The heat of fusion in the heating and cooling processes was $162.3 \mathrm{~kJ} / \mathrm{kg}$ and $162.1 \mathrm{~kJ} / \mathrm{kg}$ respectively. The onset temperatures for the heating and cooling were $22.27^{\circ} \mathrm{C}$ and $22.06^{\circ} \mathrm{C}$, respectively, while the peak temperatures for the heating and cooling were $26.21^{\circ} \mathrm{C}$ and $20.68^{\circ} \mathrm{C}$, respectively. Fig. 5 b) shows the $h-T$ relationship of the PCM S21. 


\subsection{PCM charging and discharging processes}

To understand the heat transfer characteristics of the PCM TES unit during a phase change process, an experiment was carried out based on the test condition specified for Trial test 1 in the Taguchi experimental plan (see Table 3). Before the experiment, the temperature of the PCM bricks in the TES unit was first cooled by the chiller and heat exchanger to around $14^{\circ} \mathrm{C}$, and the heated air from the PVT emulator was then directed to the PCM TES unit for thermal heat charge once the temperature of the heated air from the PVT emulator reached the desired temperature. The PCM charging mode continued until the temperature of the outlet air from the PCM TES unit was close to the inlet air temperature, after which the system was then switched to the PCM discharging mode option A (see Fig. 1b)). The thermal discharging process was completed when the temperature of the PCM bricks was decreased to around $14^{\circ} \mathrm{C}$. It is worthwhile to note that during the PCM charging process, the temperature sensors \#2 and \#5 measured the air temperature at the inlet and outlet of the PCM TES unit respectively, whereas, during the PCM thermal discharging process, their measurements were opposite due to a reverse air flow direction.

The outlet air temperature from the PVT emulator, the inlet and outlet air temperatures of the PCM TES unit, as well as the measured PCM temperatures in the two PCM bricks at both ends of the TES unit during the charging and discharging processes are presented in Fig. 6. It can be seen that when charging began, the air temperatures at the inlet and outlet of the PCM TES unit increased rapidly, and then, the outlet air temperature (measured by the temperature sensor \#5) experienced a period with a relatively small temperature gradient, indicating that heat was continuously charged into the PCM TES unit mainly as latent heat. The outlet air temperature then gradually increased until approaching to the inlet air temperature of $42^{\circ} \mathrm{C}$ at the end of the charging process. During the discharging process, the outlet air temperature (measured by the temperature \#2) from the PCM TES unit decreased and then slightly 
increased due to supercooling of the PCM, and then it decreased continuously to around $14^{\circ} \mathrm{C}$ at the end of the discharging process.

It can be seen that the temperature of the PCM brick close to the outlet of the PCM TES unit (measured by the temperature sensor \#4) increased rapidly at the beginning of the charging process (see Fig. 6b)), and then increased slowly until to around the $5^{\text {th }}$ hour. Afterwards, the temperature increased quickly, and then gradually approached to the inlet air temperature (measured by the temperature sensor \#2) until the end of the charging process. This data indicated that the thermal energy was mainly stored in the PCM as latent heat until the majority of the PCM was melted at around the $5^{\text {th }}$ hour, after which the heat was stored as sensible heat in the liquid-state of the PCM. A similar phenomenon occurred in the PCM brick close to the inlet of the PCM TES unit (measured by the temperature \#3) during the charging process.

To provide an insight into the performance characteristics during the effective PCM charging period, the heat transfer effectiveness of the PCM TES unit is shown in Fig. 7. It can be seen that the heat transfer effectiveness decreased continuously during the charging process, and due to the phase change of the PCMs, there was a relatively small variation in the heat transfer effectiveness within the effective PCM charging time period. A relatively small variation in the heat transfer effectiveness after the effective PCM charging period was also observed and this variation was mainly resulted by the small difference in the temperature between the PCM bricks and the air passing through the air channels. Since the initial PCM temperature was lower than the low limit of the PCM phase change range, the heat transfer effectiveness at the beginning of the charging process was greater than $100 \%$ due to the impact of the sensible energy stored in the solid PCM. This phenomenon has also been discussed by Tay et al. [31] and Amin et al. [14]. The similar experimental process was also 
used for the other trial tests specified in the Taguchi experimental plan, and the detailed experimental results were provided in Fig. 8.

\subsection{Taguchi experimental results and data analysis}

\subsubsection{Average heat transfer effectiveness}

The average heat transfer effectiveness and the corresponding $S / N$ ratio of each Taguchi experiment are summarised in Table 4. It can be seen that the average heat transfer effectiveness and $S / N$ ratios of all experiments varied from 22.74 to $81.68 \%$ and from -12.87 to -1.76 , respectively. The 'mean' average heat transfer effectiveness and $S / N$ ratios for each level of the control factors are presented in Table 5. The optimal combination of the control factor levels can be identified by selecting the levels with the highest $S / N$ ratios. The optimal values identified in terms of the average heat transfer effectiveness were $42.0^{\circ} \mathrm{C}, 50.0 \mathrm{l} / \mathrm{s}, 5$ and 5 for the inlet air temperature of the PCM TES unit $\left(T_{\text {air, in }}\right)$, the air flow rate $\left(Q_{v}\right)$, the number of PCM bricks in the direction of air flow $(M)$ and the number of air channels $(N)$, respectively. It can also be seen that the maximum $S / N$ ratio differences between the three different levels for the air flow rate, the number of PCM bricks in the direction of air flow, and the number of air channel were much higher than that of the inlet air temperature. This indicated that the inlet air temperature had a less impact on the average heat transfer effectiveness.

\subsubsection{Effective PCM charging time}

The effective PCM charging time and corresponding $S / N$ ratio of each Taguchi experiment are also summarised in Table 4. It can be seen that the effective PCM charging time and $S / N$ ratios of all experiments ranged from 3.51 to 17.20 hours, and from -24.71 to 10.90, respectively. Table 6 shows the response of the effective PCM charging time, including the mean effective PCM charging time and $S / N$ ratios for each level of the control factors. The number of PCM bricks in the direction of air flow was ranked as the least 
significant control factor (i.e. maximum $S / N$ ratio difference between the three different levels of 1.315). The optimal design for the effective PCM charging time was identified as $42.0^{\circ} \mathrm{C}$, $150.0 \mathrm{l} / \mathrm{s}, 3$ and 4 for the inlet air temperature of the PCM TES unit, the air flow rate, the number of PCM bricks in the direction of air flow, and the number of air channels, respectively.

\section{Results of multi-objective optimisation and multi-criteria decision-making}

The two performance models were first trained through regressions, based on the experimental results. The identified coefficients of $a_{0}-a_{3}$ in Eq. (5) were $-35.425,8.2838$, 0.37 and 0.0052 while those of $b_{0}-b_{3}$ in Eq. (11) were 20.1218, -8.3341, 1.1504, and $0.695 \times 10^{-3}$, respectively. The resulting coefficients of determination $\left(R^{2}\right)$ for the performance models of the average heat transfer effectiveness and the effective PCM charging time were 0.937 and 0.9889 , respectively. It is worthwhile to mention that, in this study, a simplified approach was used to formulate the two performance models in order to utilise the experimental data to facilitate the optimisation. Due to the model prediction errors, a confirmation test was recommended to validate the optimisation result. For different PCM TES systems, the model coefficients used should be determined based on the performance data of the system of concern. It is worthwhile to note that the performance models need to be recalibrated if they are used in different working conditions or different operating ranges far from that used in this study.

\subsection{Results of multi-objective optimisation}

In order to handle the discrete variables (i.e. the number of PCM bricks in the direction of air flow and the number of air channels), the multi-objective optimisation problem was carried out for each combination of the numbers of the PCM bricks in the direction of air flow and the air channels (i.e. $M \times N$ combinations) individually. As a result, the Pareto fronts for 
each combination of $M$ and $N$ can be identified and are presented in Fig. 9. The initial population of the multi-objective controlled elitist GA used was 200 with a crossover fraction of 0.8 , a uniform mutation rate of 0.01 and a Pareto fraction of 0.3 . An overall Pareto front (marked as red circles in Fig. 8) can be further identified among the Pareto fronts with different $M \times N$ combinations using non-dominated sorting algorithm. The resulting overall Pareto front was mainly on the Pareto fronts of the $M \times N$ combinations of $5 \times 5$ and $5 \times 4$ although a small part of the Pareto fronts of the $M \times N$ combinations of $3 \times 4,4 \times 5,4 \times 4,3 \times 3$ and $5 \times 3$ was also included. The overall Pareto front achieved can be used to facilitate the optimal design of the PCM TES unit. For instance, an optimal design at the bottom part of the figure, which had a small effective PCM charging time, could be more applicable for the weather conditions with short solar radiation periods, while an optimal design at the top right side of the figure with a large average heat transfer effectiveness could be preferred when solar radiation is sufficient during the daytime.

\subsection{Results of multi-criteria decision-making (MCDM)}

The overall Pareto front presented all candidates of the optimal designs for the PCM TES unit. A multi-criteria decision-making using the compromise ranking method (VIKOR) was then conducted to further select the compromise optimal solution(s). In this study, the weighting factor $(v)$ in Eq. (14) was set as 0.8 to give more importance to $L_{1}$-metric.

The MCDM was carried out for three cases with different weighting factors $(w)$ for the average heat transfer effectiveness and the effective PCM charging time. In Case 1, the same weighting factor $(w)$ of 0.5 was assigned for the average heat transfer effectiveness and the effective PCM charging time, while different weighting factors $(w)$ of $0.1 / 0.9$ and $0.9 / 0.1$ were assigned for the two KPIs under Case 2 and Case 3, respectively. By implementing VIKOR analysis, 5, 9 and 8 compromise solutions were identified for Cases 1, 2 and 3 respectively, as summarised in Table 7. 
It can be seen that the resulted KPIs corresponding to the compromise solutions identified for each case were very close to each other, so any of them could be considered as an optimal solution for individual cases. However, the identified optimal solutions and the resulting average heat transfer effectiveness of the PCM TES and the effective PCM charging time were significantly different for three different cases. The highest average heat transfer effectiveness of the PCM TES unit occurred in Case 3, followed by Case 1 and Case 2, while the lowest effective PCM charging time of the PCM TES unit was observed in Case 2, followed by Case 1 and Case 3. This showed the importance of selecting appropriate weighting factors $(w)$ for the optimisation problem. The weighting factors close to those used in Case 3 can be considered for weather conditions with a long sufficient solar radiation period during the daytime, while the weighting factors close to that used in Case 2, which can reduce the effective PCM charging time through sacrificing the average heat transfer effectiveness, can be used for weather conditions with a short solar radiation period during the daytime.

\subsection{Comparison among different designs and confirmation test for the optimal design}

An optimal design through averaging the values of the optimisation variables of the eleven compromise designs obtained through multi-objective optimisation for Case 1 (in which the inlet air temperature was set as $42^{\circ} \mathrm{C}$ ) was further compared with the baseline case (i.e. Taguchi trial test 1) and two near-optimal designs identified in Section 4.3 using the Taguchi method for individual KPIs. The two near-optimal designs achieved through $S / N$ ratio analysis were considered to be only 'near optimal' for the average heat transfer effectiveness and the effective PCM charging time, respectively. These four design options were ranked further using the measure $L_{c o m}$-metric in VIKOR and the results are presented in Table 8 . It is clearly shown that the optimal design identified by the proposed strategy was ranked as the best one with an average heat transfer effectiveness of $59.29 \%$ and the effective 
PCM charging time of $6.11 \mathrm{~h}$, followed by the baseline design. Moreover, the results also illustrated that the optimal design determined using the multi-objective optimisation outperformed those identified using Taguchi method.

To validate the performance of the PCM TES unit by using the compromise optimal design identified, a confirmation test was carried out. The resulting average heat transfer effectiveness and the effective PCM charging time from the confirmation test were $52.76 \%$ and $6.68 \mathrm{~h}$, respectively, which were close to that of $59.29 \%$ and $6.11 \mathrm{~h}$ predicted using the two performance models. The relative errors were $12.4 \%$ for the average heat transfer effectiveness and $8.5 \%$ for the effective PCM charging time, respectively. The discrepancies were mainly due to the complex heat transfer within the PCM encapsulated in the plastic containers and the thermal properties of the PCM used. The similar levels of deviations between the experimental data and model predicted values were also reported in the previous studies $[31,32]$.

\section{Conclusions}

This paper presented an experimental study and multi-objective optimisation of a PCM TES unit for solar air systems. The performance of the PCM TES unit during the charging process was characterised using two conflicting performance indicators of the average heat transfer effectiveness and the effective PCM charging time, based on a series of Taguchi experiments. A multi-objective design optimisation strategy was then developed to facilitate optimal design of PCM TES units. The performance of the optimisation strategy was evaluated and compared with a baseline case and two single-objective near-optimal designs which were identified using signal-to-noise analysis. The key findings obtained are as follows:

- Through signal-to-noise analysis of Taguchi experimental data, it was shown that the average heat transfer effectiveness and the effective PCM charging time of using the near-optimal design identified based on the optimisation objective of the 
average heat transfer effectiveness were $85.81 \%$ and $10.94 \mathrm{~h}$ respectively, while those were $24.30 \%$ and $3.56 \mathrm{~h}$ respectively when using the effective PCM charging time as the optimisation objective.

- An optimal Pareto front was identified and a number of compromise solutions with different weighting factors were achieved through considering the trade-offs between the two optimisation objectives by using the proposed optimisation strategy.

- The average heat transfer effectiveness and the effective PCM charging time using the optimal design identified with the weighting factors of $0.5 / 0.5$ were $59.29 \%$ and $6.11 \mathrm{~h}$ respectively, which outperformed the two single-objective near-optimal designs.

- The proposed multi-objective optimisation strategy which takes into account two different objectives can result in a more reasonable solution.

These findings obtained and the methodology used to develop the optimisation strategy can be potentially used to facilitate optimal design of other energy systems.

\section{Acknowledgements}

The authors would sincerely thank Professor Paul Cooper, Dr Massimo Fiorentini and Mr Steven Beltrame for the primary design and commissioning of the test rig.

\section{References}

[1] Chen X.J., Worall M., Omer S., Su Y.H. and Riffat S. 2014, 'Experimental investigation on PCM cold storage integrated with ejector cooling system', Applied Thermal Engineering, vol.63, pp.419-427.

[2] Butler D. 2008, 'Architecture: architects of low-energy future', Nature, vol.452, no.7187, pp.520-523. 
638 [3] Perez-Lombard L., Ortiz J. and Pout C. 2008, 'A review on buildings energy consumption 639 information', Energy and Buildings, vol.40, pp.394-398.

640 [4] Wang S., Ma Z. and Gao D.C. 2010, 'Performance enhancement of a complex chilled water system using a check valve: experimental validation', Applied Thermal Engineering, 642 vol. 30, pp. 2827-2832.

643 [5] Zalba B. and Marin J.M. 2003, 'Review on thermal energy storage with phase change: materials, heat transfer analysis and applications', Applied Thermal Engineering, vol.23, pp.251-283.

646

[6] Saitoh H., Hamad Y., Kubota H., Nakamura M., Ochifuji K., Yokoyama S. and Nagano K. 647 2003, 'Field experiments and analyses on a hybrid solar collector', Applied Thermal 648 Engineering, vol.23, pp.2089-2105

649 [7] Huang S., Ma Z., Cooper P. 2014, 'Optimal design of vertical ground heat exchangers by 650 using entropy generation minimization method and genetic algorithms', Energy Conversion and Management, vol.87, no.11, pp.128-137.

652

[8] Labat M., Virgone J., David D. and Kuznik F. 2014, 'Experimental assessment of a PCM to air heat exchanger storage system for building ventilation application', Applied Thermal Engineering, vol.66, pp.375-382.

[9] Chen C., Liang L., Zhang Y., Chen Z.G. and Xie G. 2014, 'Heat transfer performance and structural optimisation design method of vertical phase change thermal energy storage device', Energy and Buildings, vol.68, pp.679-685.

658 [10] Lin W., Ma Z., Sohel M.I. and Cooper P. 2014, 'Development and evaluation of a ceiling 659 ventilation system enhanced by solar photovoltaic thermal collectors and phase change materials', Energy Conversion and Management, vol.88, pp.218-230. 
661

662

663

664

665

666

667

668

669

670

671

672

673

674

675

676

677

678

679

680

681

682

683

684

685

686

[11] Fiorentini M., Wall J., Ma Z., Braslavsky J. and Cooper P. 2017, 'Hybrid model predictive control of a residential HVAC system with on-site thermal energy generation and storage', Applied Energy, vol.187, pp.465-479.

[12] Stritih U., Charvat P., Koželj R., Klimes L., Osterman E., Ostry M. and Butala V. 2018, 'PCM thermal energy storage in solar heating of ventilation air-Experimental and numerical investigations', Sustainable Cities and Society, vol.37, pp.104-115.

[13] Dolado P., Lazaro A., Marin J.M. and Zalba B. 2011, 'Characterization of melting and solidification in a real scale PCM-air heat exchanger: Numerical model and experimental validation', Energy Conversion and Management, vol.52, pp.1890-1907.

[14] Waqas A. and Kumar S. 2013, 'Phase change material (PCM)-based solar air heating system for residential space heating in winter', International Journal of Green Energy, vol.10, pp.402-426.

[15] Diarce G., Celador A.C, Sala J.M. and Romero A., 2018, 'A novel correlation for the direct determination of the discharging time of plate-based latent heat thermal energy storage systems', Applied Thermal Engineering, vol.129, pp. 521-534.

[16] Ren H., Lin W., Ma Z., and Fan W. 2017, 'Thermal performance evaluation of an integrated photovoltaic thermal-phase change material system using Taguchi method', Energy Procedia, vol.121, pp.118-125.

[17] Amin N.A.M, Belusko M., Bruno F. and Liu M. 2012, 'Optimising PCM thermal storage systems for maximum energy storage effectiveness', Solar Energy, vol.86, pp.2263-2272.

[18] Saman W., Bruno F. and Halawa E. 2005, 'Thermal performance of PCM thermal storage unit for a roof integrated solar heating system', Solar Energy, vol.78, no.2, pp.341349.

[19] Charvat P., Klimes L. and Ostry M. 2014, 'Numerical and experimental investigation of a PCM-based thermal storage unit for solar air system', Energy and Buildings, vol.68, pp.488497. 
687

688

689

690

691

692

693

694

695

696

697

698

699

700

701

702

703

704

705

706

707

708

709

710

711

[20] Meyer U.B., Creux S.E. and Marin A.K.W. 2007, 'Process oriented analysis: design and optimisation of industrial production systems', Taylor \& Francis, London.

[21] Carlucci S., Cattarin G., Causone F. and Pagliano L. 2015, 'Multi-objective optimizaiton of a nearly zero-energy building based on thermal and visual discomfort minimization using a non-dominated sorting genetic algorithm (NSGA-II)', Energy and Buildings, vol.104, pp.378394.

[22] Huang S., Ma Z. and Wang F. 2015, 'A multi-objective design optimisation strategy for vertical ground heat exchangers', Energy and Buildings, vol.87, no.1, pp.233-242.

[23] Padovan R. and Manzan M. 2014, 'Genetic optimisation of a PCM enhanced storage tank for solar domestic hot water systems', Solar Energy, vol.103, pp.563-73.

[24] Futrell B.J., Ozelkan E.C. and Brentrup D. 2015, 'Bi-objective optimisation of building enclosure design for thermal and lighting performance', Building and Environment, vol.92, pp.591-602.

[2525] Wong J.Y.Q., Sharma S. and Rangaiah G.P. 2016, 'Design of shell-and-tube heat exchangers for multiple objectives using elitist non-dominated sorting genetic algorithm with termination criteria', Applied Thermal Engineering, vol.93, pp.888-899.

[26] Lahiri S.K., Khalfe N.M. and Wadhwa S.K. 2012, 'Particle swarm optimization technique for the optimal design of shell and tube heat exchangers', Chemical Product and Process Modelling, vol.7, no.1, Article 14.

[27] Singh K. and Das R. 2016, 'An experimental and multi-objective optimisation study of a forced draft cooling tower with different fills', Energy Conversion and Management, vol.111, pp.417-430.

[28] PCM. Phase Change Material products Limited <http://pcmproducts.net/home.htm>, [accessed 23.03/2016]

[29] Schneider Electric, < http://www.schneider-electric.com.au>, [accessed 23.03.2016]. 
712 [30] Taguchi G., Chowdhury S. and Wu Y. 2004, 'Taguchi's quality engineering handbook',

713

714

715

716

717

718

719

720

721

722

723

724

725

726

727

728

729

730

731

732

733

734

735

736

737 Wiley, New Jersey, USA.

[31] Tay N.H.S., Belusko M. and Bruno F. 2012, 'Experimental investigation of tubes in a phase change thermal energy storage system', Applied Energy, vol.90, pp.288-297.

[32] Tay N.H.S., Belusko M. and Bruno F. 2012, 'An effectiveness-NTU technique for characterising tube-in-tank phase change thermal energy storage systems', Applied Energy, vol.91, pp.309-319.

[33] Bergman T.L., Lavine A.S., Incropera P.F., Dewitt P.D. 2011, 'Fundamental of heat and mass transfer', 7th edition, John Wiley \& Sons, Hoboken, New Jersey, USA.

[34] Ma Z., Lin W. and Sohel M.I. 2015, 'Nano-enhanced phase change materials for improved building performance', Renewable and Sustainable Energy Reviews, vol.5, pp.1256-1268.

[35] Deb K., Agrawal S, Pratap A. and Meyarivan T. 2000, 'A fast elitist non-dominated sorting genetic algorithm: NSGA-II', Lecture Notes in Computer Science 1917, pp. 849-858.

[36] Mathwork, <http://au.mathworks.com/help/gads/examples/multiobjective-geneticalgorithm-options.html>, [accessed 23.03.2016].

[37] Opricovic S. 1998, 'Multi-criteria optimisation of civil engineering systems', Faculty of Civil Engineering, Balgrade.

[38] Opricovic S. and Tzeng G.H. 2004, 'Compromise solution by MCDM methods: a comparative analysis of VIKOR and TOPSIS', European Journal of Operational Research, vol.156, pp.445-455.

[39] Caterino N. 2009, 'Comparative analysis of multi-criteria decision-making methods for seismic structural retrofitting', Computer-Aided Civil and Infrastructure Engineering, vol.24, pp.432-445. 
Table 1 Thermo-physical properties of PCM S21 [22]

\begin{tabular}{ll}
\hline Properties & Value \\
\hline Nominal phase change temperature $\left({ }^{\circ} \mathrm{C}\right)$ & 22 \\
Density $\left(\mathrm{kg} / \mathrm{m}^{3}\right)$ & 1,530 \\
Nominal latent heat capacity $(\mathrm{kJ} / \mathrm{kg})$ & 170 \\
Thermal conductivity $(\mathrm{W} /(\mathrm{m} \cdot \mathrm{K}))$ & 0.54 \\
Specific heat capacity $(\mathrm{kJ} /(\mathrm{kg} \cdot \mathrm{K}))$ & 2.2 \\
\hline
\end{tabular}

Table 2 Major measurement instruments used and the claimed uncertainties

\begin{tabular}{|c|c|c|c|c|}
\hline Instrument & Function & Location & $\begin{array}{l}\text { Measurement } \\
\text { range }\end{array}$ & Accuracy \\
\hline $\begin{array}{l}\text { C-Bus digital } \\
\text { temperature } \\
\text { sensors }\end{array}$ & $\begin{array}{l}\text { Temperature } \\
\text { measurement }\end{array}$ & $\begin{array}{l}\text { Each end of the PCM } \\
\text { TES duct; PVT } \\
\text { emulator outlet; Inside } \\
\text { of the } \\
\text { PCM bricks }\end{array}$ & $-10-80^{\circ} \mathrm{C}$ & $\pm 0.5^{\circ} \mathrm{C}$ \\
\hline $\begin{array}{c}\text { SIMENS } \\
\text { QBMv66.201 }\end{array}$ & $\begin{array}{l}\text { Differential } \\
\text { pressure } \\
\text { measurement }\end{array}$ & $\begin{array}{l}\text { Each end of the PCM } \\
\text { TES duct }\end{array}$ & $0-200 \mathrm{~Pa}$ & $\begin{array}{l} \pm 3 \% \text { of the full } \\
\text { scale }\end{array}$ \\
\hline $\begin{array}{l}\text { SIMENS } \\
\text { QVM62.1 }\end{array}$ & $\begin{array}{c}\text { Air velocity } \\
\text { measurement }\end{array}$ & $\begin{array}{l}\text { Inlet of the PCM duct } \\
\text { at the charging mode }\end{array}$ & $0-10 \mathrm{~m} / \mathrm{s}$ & $\begin{array}{l} \pm 0.2 \mathrm{~m} / \mathrm{s}+3 \% \text { of } \\
\text { the measured value }\end{array}$ \\
\hline
\end{tabular}

Table 3 Taguchi experimental plan and factor levels

\begin{tabular}{lllll}
\hline \multirow{2}{*}{$\begin{array}{l}\text { Trail } \\
\text { test }\end{array}$} & $\begin{array}{l}\text { Control air temperature of } \\
\text { the TES unit }\left({ }^{\circ} \mathrm{C}\right)\end{array}$ & $\begin{array}{l}\text { Charging air } \\
\text { flow rate }(\mathrm{l} / \mathrm{s})\end{array}$ & $\begin{array}{l}\text { Number of PCM bricks } \\
\text { along the TES unit }\end{array}$ & $\begin{array}{l}\text { Number of air } \\
\text { channels }\end{array}$ \\
\hline 1 & $42.0($ level 1) & $100.0($ level 1) & 4 (level 1) & 4 (level 1) \\
2 & 42.0 & $50.0($ level 2) & $5($ level 2) & 5 (level 2) \\
3 & 42.0 & $150.0($ level 3) & 3 (level 3) & 3 (level 3) \\
4 & $37.0($ level 2) & 100.0 & 5 & 3 \\
5 & 37.0 & 50.0 & 3 & 4 \\
6 & 37.0 & 150.0 & 4 & 5 \\
7 & $32.0($ level 3) & 100.0 & 3 & 5 \\
8 & 32.0 & 50.0 & 4 & 3 \\
9 & 32.0 & 150.0 & 5 & 4 \\
\hline
\end{tabular}


Table 4 Taguchi experimental results

\begin{tabular}{|c|c|c|c|c|c|c|}
\hline \multirow{2}{*}{ No. } & \multicolumn{2}{|c|}{$\begin{array}{c}\text { Average value of variables in the } \\
\text { experiments }\end{array}$} & \multicolumn{2}{|c|}{$\bar{\varepsilon}_{c h}$} & \multicolumn{2}{|c|}{$\Delta t_{c h}$} \\
\hline & $T_{a t r, t n}\left({ }^{\circ} \mathrm{C}\right)$ & $Q_{v}(1 / s)$ & Value $(\%)$ & $S / N$ & Value (h) & $S / N$ \\
\hline 1 & 42.03 & 102.34 & 44.25 & -7.08 & 4.53 & -13.11 \\
\hline 2 & 42.03 & 51.09 & 81.68 & -1.76 & 10.84 & -20.70 \\
\hline 3 & 42.14 & 153.44 & 22.74 & -12.87 & 3.51 & -10.90 \\
\hline 4 & 37.03 & 102.11 & 36.71 & -8.70 & 6.86 & -16.72 \\
\hline 5 & 36.78 & 50.48 & 40.50 & -7.85 & 9.58 & -19.62 \\
\hline 6 & 37.18 & 149.26 & 43.74 & -7.18 & 6.39 & -16.11 \\
\hline 7 & 32.27 & 103.24 & 35.74 & -8.94 & 11.67 & -21.34 \\
\hline 8 & 31.62 & 51.30 & 33.05 & -9.62 & 17.20 & -24.71 \\
\hline 9 & 32.2 & 151.74 & 37.38 & -8.55 & 8.30 & -18.38 \\
\hline
\end{tabular}

749

750

751

Table 5 Response table for the average heat transfer effectiveness

\begin{tabular}{|c|c|c|c|c|c|c|c|c|}
\hline \multirow{2}{*}{ Level } & \multicolumn{2}{|c|}{$T_{a t r, t n}$} & \multicolumn{2}{|c|}{$Q_{v}$} & \multicolumn{2}{|c|}{$M$} & \multicolumn{2}{|c|}{$N$} \\
\hline & $\overline{\varepsilon_{c h}}$ & $S / N$ & $\overline{\varepsilon_{c h}}$ & $S / N$ & $\overline{\varepsilon_{c h}}$ & $S / N$ & $\overline{\varepsilon_{c h}}$ & $S / N$ \\
\hline 1 & $49.56 \%$ & -7.23 & $38.90 \%$ & -8.24 & $40.35 \%$ & -7.96 & $40.71 \%$ & -7.83 \\
\hline 2 & $40.32 \%$ & -7.91 & $51.74 \%$ & -6.41 & $51.92 \%$ & -6.34 & $53.72 \%$ & -5.96 \\
\hline 3 & $35.39 \%$ & -9.03 & $34.62 \%$ & -9.53 & $32.99 \%$ & -9.88 & $30.83 \%$ & -10.40 \\
\hline Optimal & \multicolumn{2}{|c|}{ Level 1} & \multicolumn{2}{|c|}{ Level 2} & \multicolumn{2}{|c|}{ Level 2} & \multicolumn{2}{|c|}{ Level 2} \\
\hline$S / N_{\max }-S / N_{\min }$ & \multicolumn{2}{|c|}{1.8} & \multicolumn{2}{|c|}{3.12} & \multicolumn{2}{|c|}{3.55} & \multicolumn{2}{|c|}{4.44} \\
\hline Rank & \multicolumn{2}{|c|}{4} & \multicolumn{2}{|c|}{3} & \multicolumn{2}{|c|}{2} & \multicolumn{2}{|c|}{1} \\
\hline
\end{tabular}

753

Table 6 Response table for the effective PCM charging time

\begin{tabular}{|c|c|c|c|c|c|c|c|c|}
\hline \multirow[b]{2}{*}{ Level } & \multicolumn{2}{|c|}{$T_{a t r, t n}$} & \multicolumn{2}{|c|}{$Q_{v}$} & \multicolumn{2}{|c|}{$M$} & \multicolumn{2}{|c|}{$N$} \\
\hline & $\begin{array}{c}\Delta t_{c h} \\
(\mathrm{~h})\end{array}$ & $S / N$ & $\begin{array}{c}\Delta t_{c h} \\
(\mathrm{~h})\end{array}$ & $S / N$ & $\begin{array}{l}\Delta t_{c h} \\
(\mathrm{~h})\end{array}$ & $S / N$ & $\begin{array}{l}\Delta t_{c h} \\
(\mathrm{~h})\end{array}$ & $S / N$ \\
\hline 1 & 6.29 & -14.91 & 7.68 & -17.06 & 9.37 & -17.98 & 7.47 & -17.04 \\
\hline 2 & 7.61 & -17.49 & 12.54 & -21.68 & 8.67 & -18.60 & 9.63 & -19.38 \\
\hline 3 & 12.39 & -21.48 & 6.07 & -15.13 & 8.25 & -17.29 & 9.19 & -17.45 \\
\hline Optimal & \multicolumn{2}{|c|}{ Level 1} & \multicolumn{2}{|c|}{ Level 3} & \multicolumn{2}{|c|}{ Level 3} & \multicolumn{2}{|c|}{ Level 1} \\
\hline$S / N_{\text {max }}-S / N_{\text {min }}$ & \multicolumn{2}{|c|}{6.57} & \multicolumn{2}{|c|}{6.55} & \multicolumn{2}{|c|}{1.31} & \multicolumn{2}{|c|}{2.35} \\
\hline Rank & \multicolumn{2}{|c|}{1} & \multicolumn{2}{|c|}{2} & \multicolumn{2}{|c|}{4} & \multicolumn{2}{|c|}{3} \\
\hline
\end{tabular}


Table 7 Results of multi-criteria decision-making based on overall Pareto front

\begin{tabular}{cccccccc}
\hline Case & $\begin{array}{c}\text { Rank } \\
\text { of } Q_{j}\end{array}$ & $T_{\text {atr }, \text { tn }}\left({ }^{\circ} \mathrm{C}\right)$ & $Q_{v}(1 / \mathrm{s})$ & $M$ & $N$ & $\bar{\varepsilon}_{c h}(\%)$ & $\Delta t_{c h}(\mathrm{~h})$ \\
\hline Case 1 & 1 & 41.95 & 81.19 & 5.00 & 4.00 & 60.08 & 6.25 \\
& 2 & 41.95 & 86.31 & 5.00 & 4.00 & 58.48 & 5.99 \\
& 3 & 41.91 & 82.39 & 5.00 & 4.00 & 59.72 & 6.20 \\
& 4 & 41.85 & 80.89 & 5.00 & 4.00 & 60.17 & 6.29 \\
& 5 & 41.88 & 88.06 & 5.00 & 4.00 & 57.91 & 5.92 \\
\hline Case 2 & 1 & 42.00 & 150.00 & 4.00 & 4.00 & 31.01 & 3.68 \\
& 2 & 42.00 & 150.00 & 5.00 & 3.00 & 29.03 & 3.65 \\
& 3 & 42.00 & 149.99 & 3.00 & 4.00 & 24.30 & 3.56 \\
& 4 & 41.95 & 149.40 & 5.00 & 3.00 & 29.14 & 3.68 \\
& 5 & 42.00 & 148.34 & 3.00 & 4.00 & 24.64 & 3.60 \\
& 6 & 42.00 & 147.94 & 5.00 & 4.00 & 37.70 & 3.87 \\
& 7 & 42.00 & 147.71 & 4.00 & 4.00 & 31.58 & 3.74 \\
& 8 & 41.99 & 149.47 & 3.00 & 3.00 & 18.66 & 3.51 \\
& 9 & 41.99 & 145.88 & 4.00 & 4.00 & 32.04 & 3.79 \\
\hline Case 3 & 1 & 41.50 & 50.04 & 5.00 & 5.00 & 85.80 & 11.09 \\
& 2 & 41.57 & 50.70 & 5.00 & 5.00 & 85.58 & 10.99 \\
& 3 & 40.74 & 50.00 & 5.00 & 5.00 & 85.81 & 11.33 \\
& 4 & 40.13 & 50.00 & 5.00 & 5.00 & 85.81 & 11.54 \\
& 5 & 41.99 & 52.55 & 5.00 & 5.00 & 84.93 & 10.67 \\
& 6 & 39.58 & 50.00 & 5.00 & 5.00 & 85.81 & 11.74 \\
& 7 & 39.27 & 50.00 & 5.00 & 5.00 & 85.81 & 11.86 \\
& 8 & 41.99 & 53.48 & 5.00 & 5.00 & 84.59 & 10.57 \\
\hline
\end{tabular}

758

759

760

Table 8 Ranking results of different alternative designs

\begin{tabular}{|c|c|c|c|c|c|c|c|}
\hline Design & Rank of $Q_{j}$ & $\begin{array}{c}T_{a t r, t n} \\
\left({ }^{\circ} \mathrm{C}\right)\end{array}$ & $Q_{v}(1 / \mathrm{s})$ & $M$ & $N$ & $\bar{\varepsilon}_{c h}(\%)$ & $\Delta t_{c h}(\mathrm{~h})$ \\
\hline Baseline case & 2 & 42.0 & 102.3 & 4 & 4 & 44.25 & 4.53 \\
\hline $\begin{array}{l}\text { Taguchi design } \\
\text { identified based on the } \\
\text { average heat transfer } \\
\text { effectiveness }\end{array}$ & 3 & 42.0 & 50.0 & 5 & 5 & 85.81 & 10.94 \\
\hline $\begin{array}{l}\text { Taguchi design } \\
\text { identified based on the } \\
\text { effective PCM charging } \\
\text { time }\end{array}$ & 4 & 42.0 & 150.0 & 3 & 4 & 24.30 & 3.56 \\
\hline $\begin{array}{l}\text { Optimal design under } \\
\text { Case } 1\end{array}$ & 1 & 42.0 & 83.8 & 5 & 4 & 59.29 & 6.11 \\
\hline
\end{tabular}




\section{Figure Captions}

764 Fig. 1 Illustration of the experimental system employed.

765 Fig. 2 Illustration of the PCM TES unit.

766 Fig. 3 Installation of the temperature sensor into the PCM brick.

767 Fig. 4 Outline of the research methodology.

768 Fig. 5 DSC curves at the scanning rate of $0.05 \mathrm{~K} / \mathrm{min}$ and the $h-T$ relationship of the PCM S21.

769 Fig. 6 Measured air temperatures and PCM temperatures.

770 Fig. 7 Heat transfer effectiveness of the TES system and the effective PCM charging period.

771 Fig. 8 Temperatures of the inlet and outlet air and temperatures of the PCM bricks near the

772 inlet and outlet of the TES unit for Trial tests 2-9.

773 Fig. 9 Pareto front of the average heat transfer effectiveness and the effective PCM charging 774 time. 


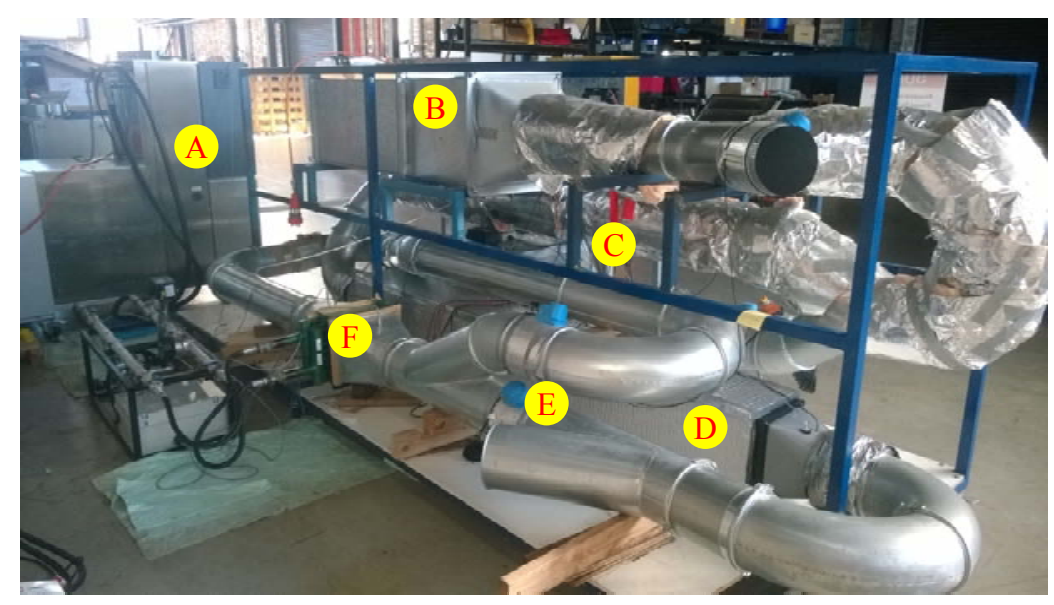

a) Lab-scale test rig.

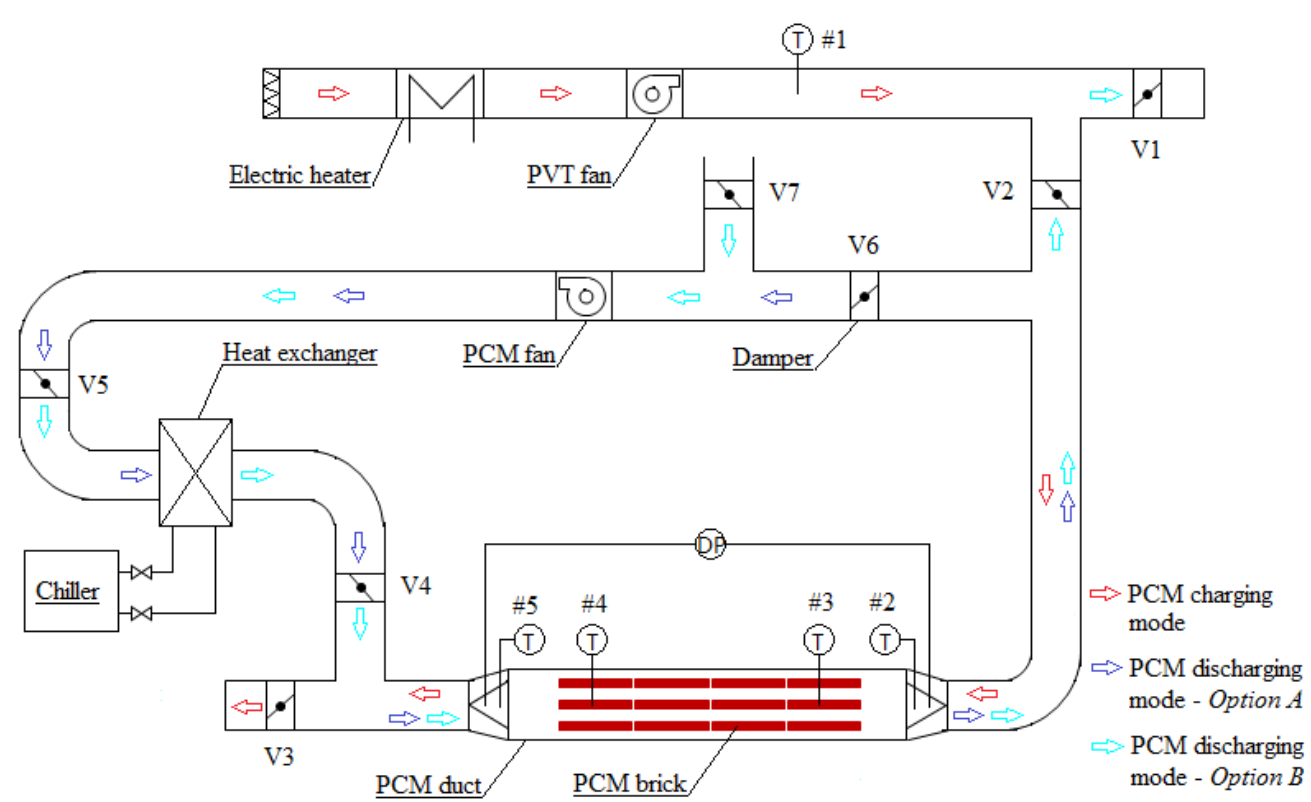

b) Simplified schematic of the lab-scale test rig.

Fig. 1 Illustration of the experimental system employed. 
789

790

791

792

793

794

795

796

797

798

799 a) Installation of the PCM bricks into the TES duct.

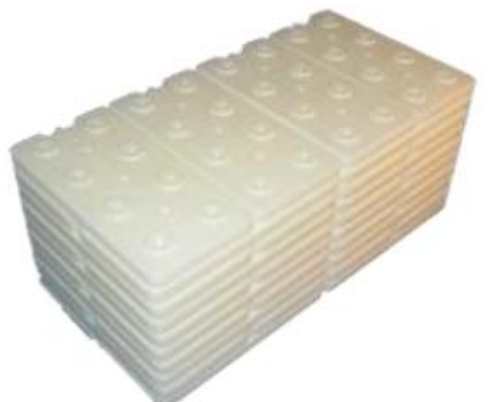

b) PCM bricks tested [22].

Fig. 2 Illustration of the PCM TES unit.

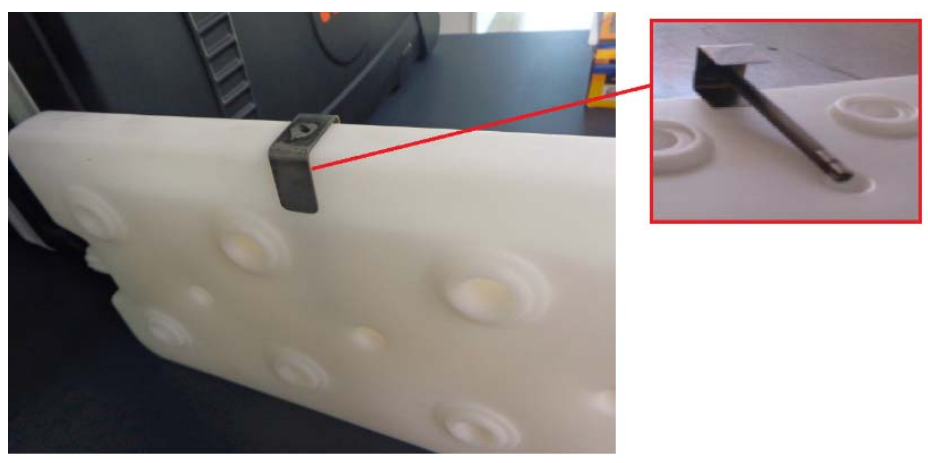

Fig. 3 Installation of the temperature sensor into the PCM brick. 


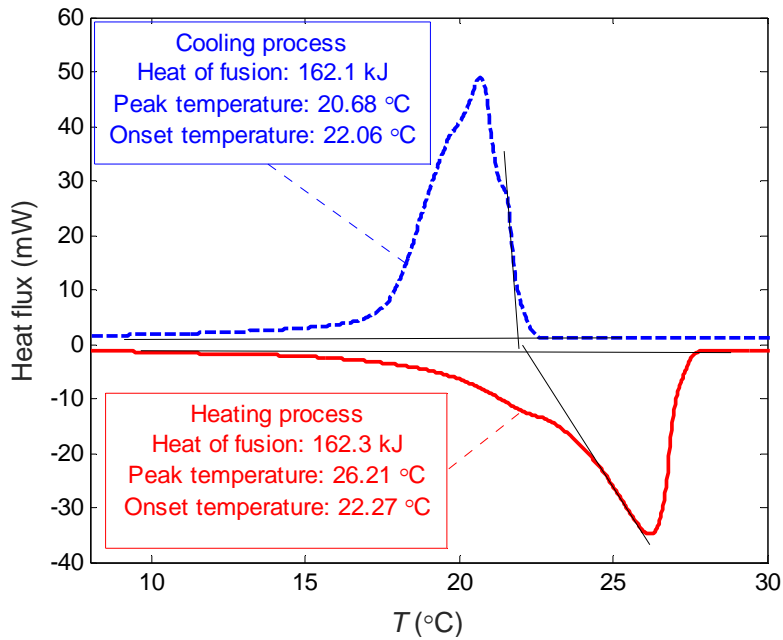

a) DSC curves

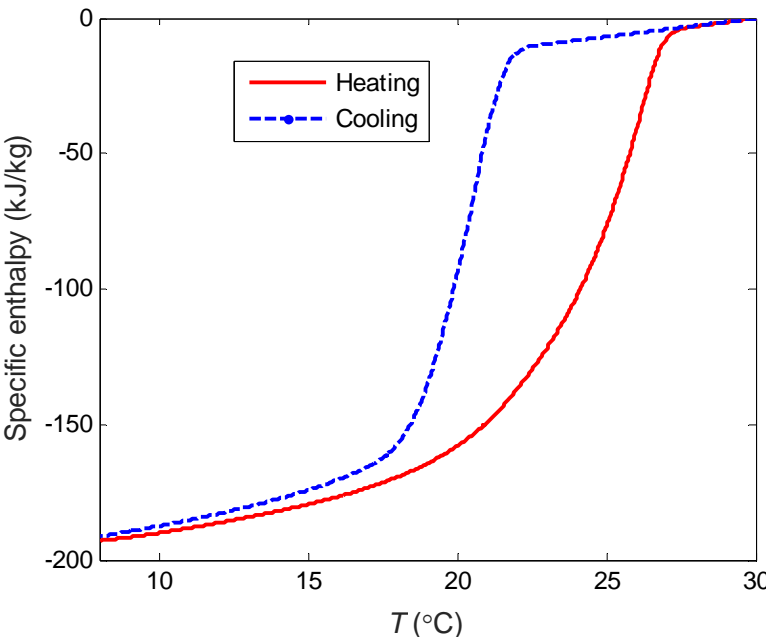

b) $h-T$ relationship
Bi-objective optimization

Fig. 4 Outline of the research methodology.

Fig. 5 DSC curves at the scanning rate of $0.05 \mathrm{~K} / \mathrm{min}$ and the $h-T$ relationship of the PCM S21. 


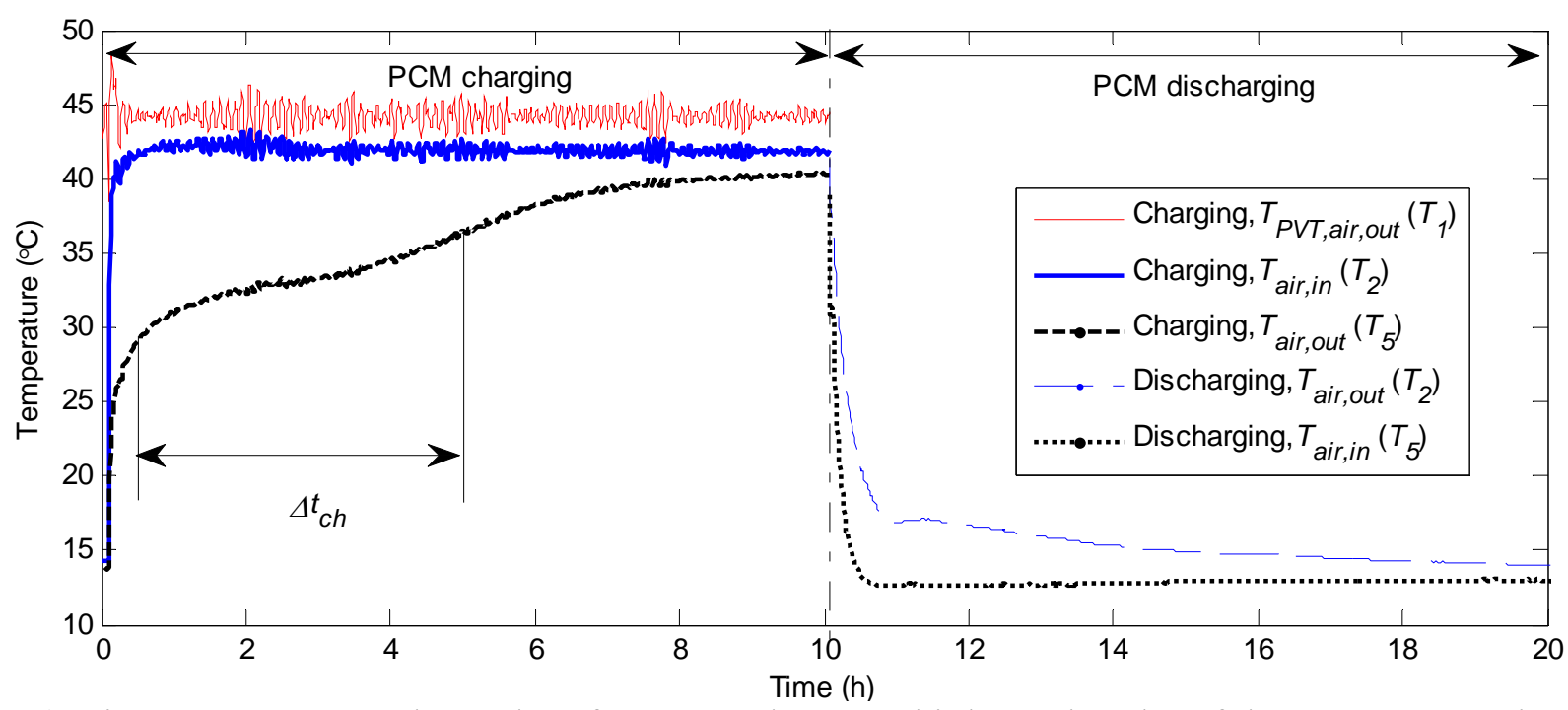

a) Air temperatures at the outlet of PVT emulator, and inlet and outlet of the PCM TES unit.



b) Temperature of the PCM bricks near the inlet and outlet of the TES unit.

Fig. 6 Measured air temperatures and PCM temperatures.

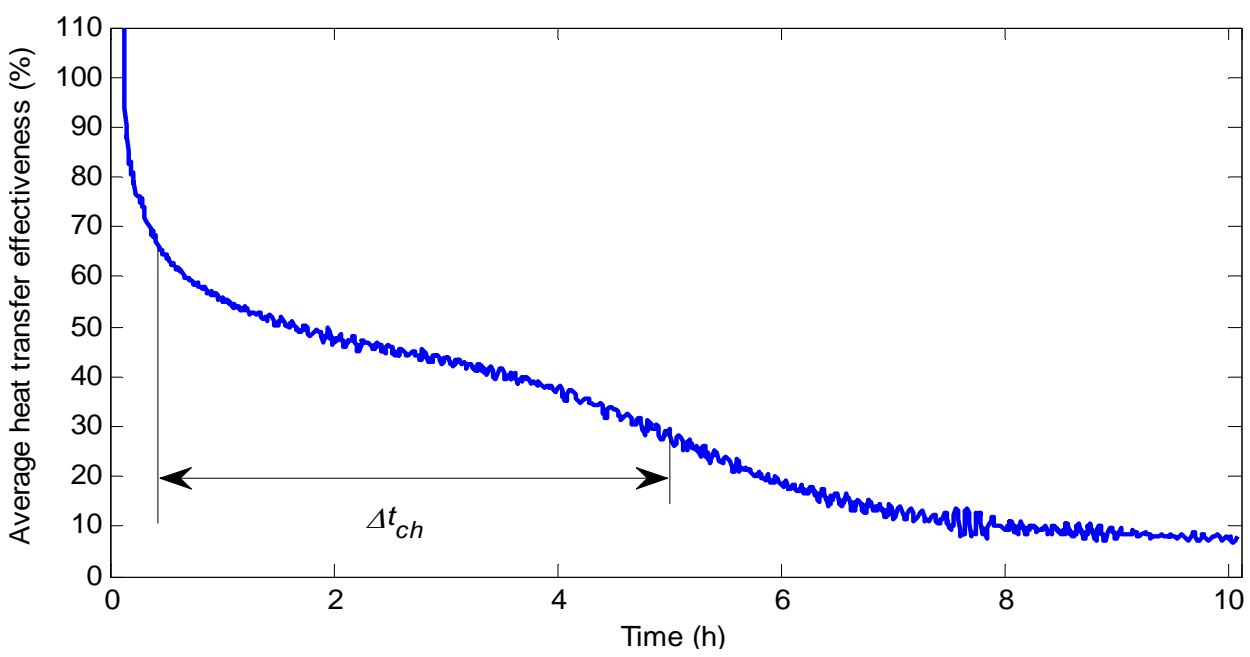

813 Fig. 7 Heat transfer effectiveness of the TES system and the effective PCM charging period. 


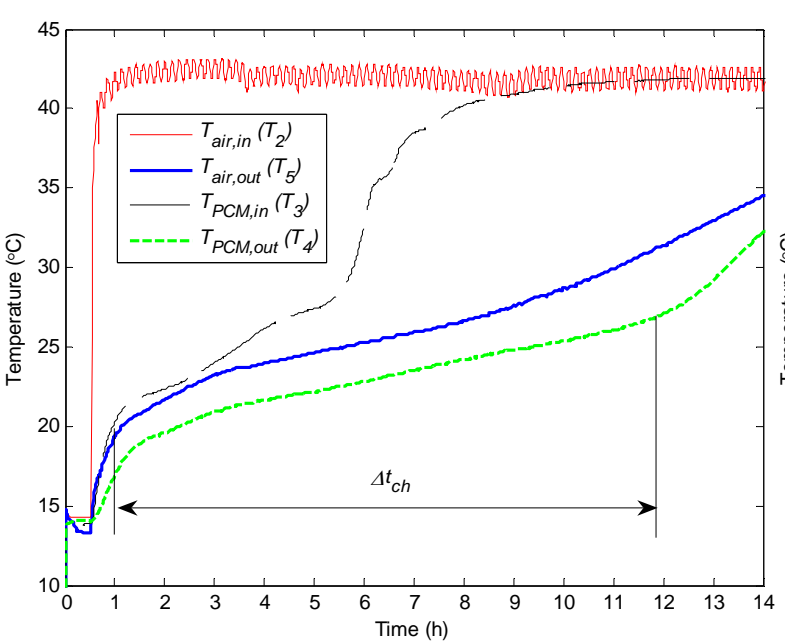

a) Trial test 2

815

816

817

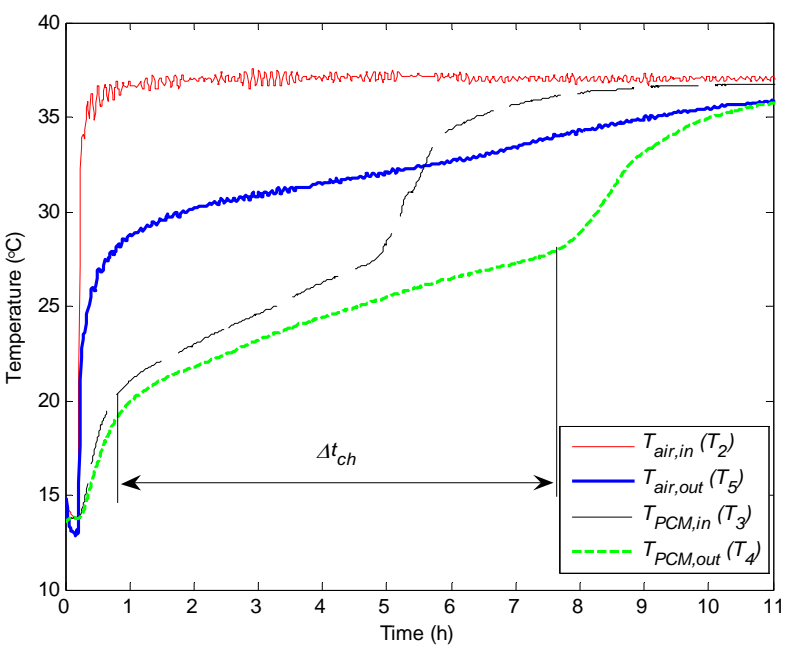

c) Trial test 4

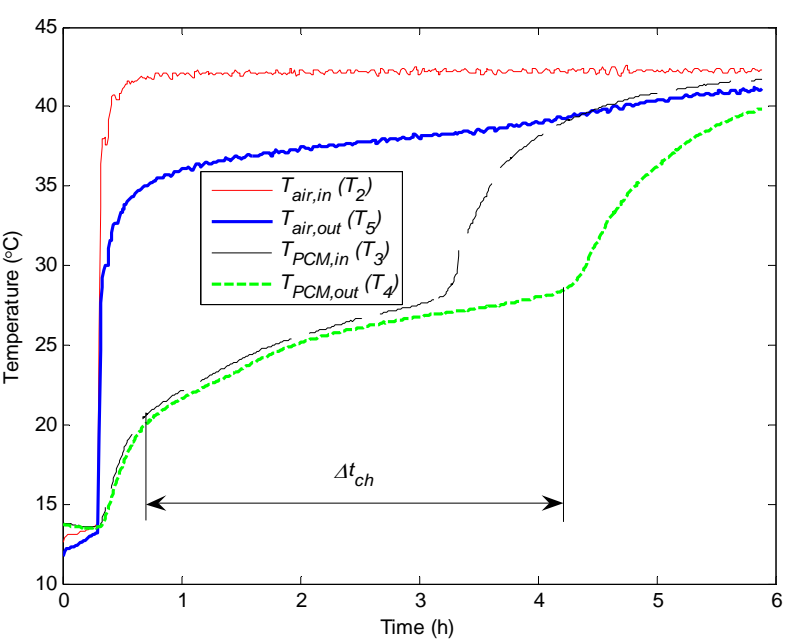

b) Trial test 3



d) Trial test 5

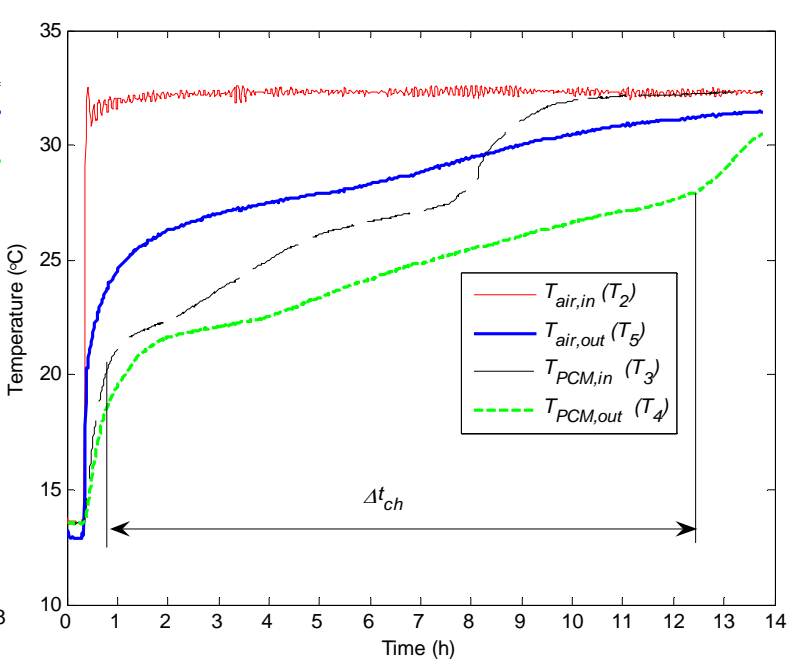

f) Trial test 7 
820

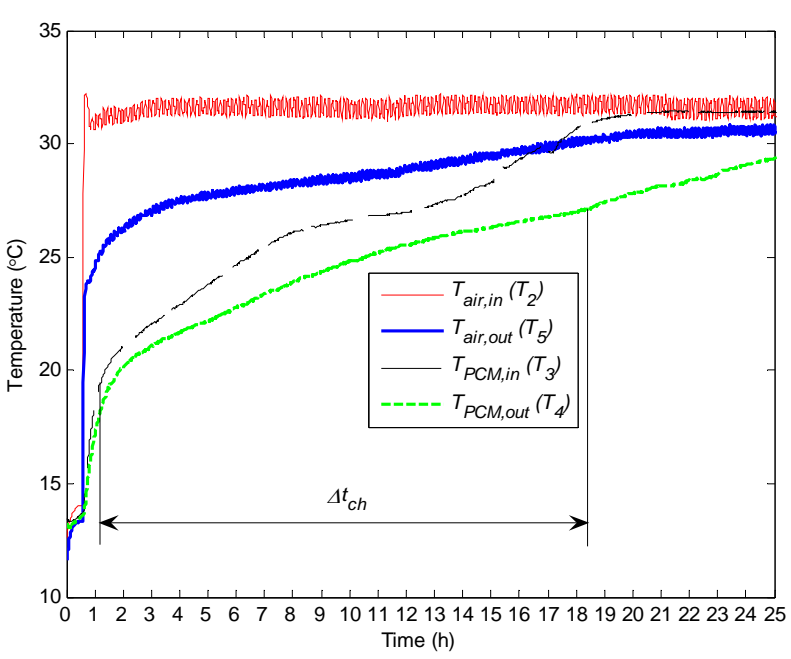

g) Trial test 8

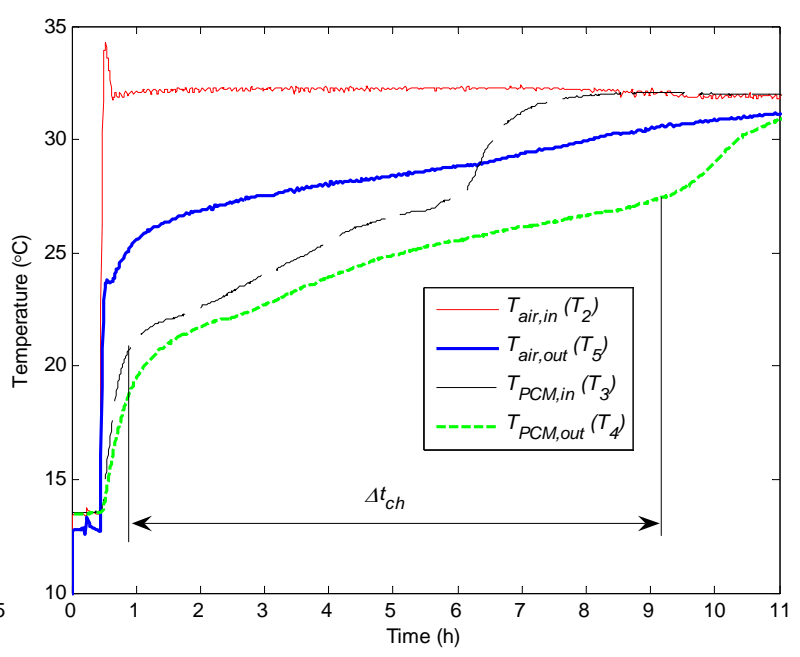

h) Trial test 9

Fig. 8 Temperatures of the inlet and outlet air and temperatures of the PCM bricks near the inlet and outlet of the TES unit for Trial tests 2-9.

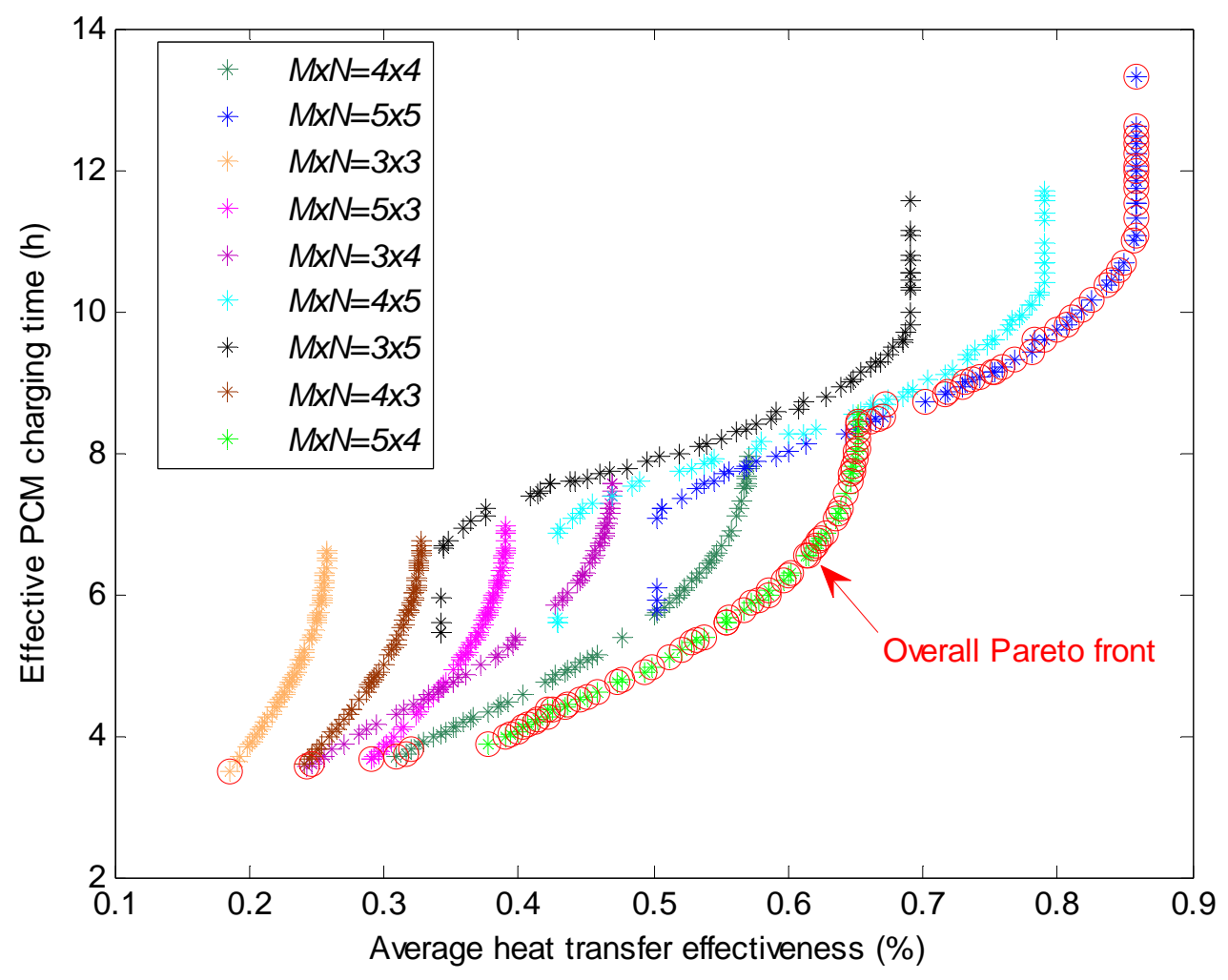

Fig. 9 Pareto front of the average heat transfer effectiveness and the effective PCM charging time. 